Background The use of general anesthesia (GA) during mechanical thrombectomy has been shown to be safe for those patients undergoing mechanical thrombectomy. One criticism of GA, however, is the extra time it takes to perform. Processes that reduce time to reperfusion can improve outcome. We sought to look at the effect of pre-transfer intubation (PTI) on patient flow and outcome.

Methods A system wide stroke program was implemented during the COVID pandemic; the program consists of a comprehensive stroke center with 10 network hospitals, 8 referring for thrombectomy. Patients were referred for mechanical thrombectomy based on AHA guidelines and VIZ AI software processing performed at the sending facilities. All patients were transferred directly to the endovascular suite. PTI was implemented for patients with high NIHSS. Data was collected from November 2020 through mid-March 2021 during the peak months of the COVID-19 surge in Georgia.

Results 52 patients underwent mechanical thrombectomy. 38 patients were from network hospital emergency departments; 19\% were COVID positive. 16 patients underwent PTI, and 22 patients were intubated in the endovascular suite. Initial NIHSS was significantly higher in PTI patients (17 versus 11, $\mathrm{p}<0.05)$. The Door-in-Door-Out time was not significantly different; $176 \pm 68 \mathrm{~min}$ with PTI and $140 \pm 37 \mathrm{~min}$ for those intubated at the CSC $(\mathrm{p}=0.065)$. Door to groin puncture at the CSC was significantly shorter for PTI, $18 \pm 6$ min, compared to those intubated at the CSC, $32 \pm 19 \mathrm{~min}$ $(\mathrm{p}<0.05)$. Despite a higher initial NIHSS, there was no significant difference in the NIHSS at discharge nor the percent of patients that were independent at discharge, mRS 0-2. There was a trend toward a larger change in NIHSS in the PTI group. There were no adverse events associated with PTI and all patients had a persistent LVO on the initial angiogram.

Conclusion An established protocol of pre-transfer intubation is safe and feasible. Intubation prior to transfer does not negatively affect DIDO yet significantly decreases door to groin time at the CSC.

Disclosures M. Stiefel: None. J. Strauss: None. J. Shapiro: None. S. Solomon: None. C. Lytle: None. T. Esdale: None. A. Schuette: None.

\section{P-021 TIGER STUDY: SHORTER ARTERIAL PUNCTURE TO REVASCULARIZATION TIMES AND FIRST PASS EFFECT IMPROVES ANGIOGRAPHIC AND CLINICAL OUTCOMES}

${ }^{1} \mathrm{~A}$ Jadhav*, ${ }^{2} \mathrm{R}$ Gupta, ${ }^{3} \mathrm{E}$ Levy, ${ }^{4} \mathrm{O}$ Zaidat, ${ }^{5} \mathrm{D}$ Yavagal, ${ }^{6} \mathrm{~J}$ Saver. ${ }^{1}$ University of Pittsburgh Medical Center, Pittsburgh, PA; ${ }^{2}$ Wellstar Medical Group, Marietta, GA; ${ }^{3}$ State University of New York at Buffalo, Buffalo, NY; ${ }^{4}$ St. Vincent Mercy Medical Center, Toledo, OH; ${ }^{5}$ University of Miami School of Medicine, Miami, FL; ${ }^{6}$ University of California Los Angeles, Los Angeles, CA

\subsection{6/neurintsurg-2021-SNIS.57}

Introduction Achieving good clinical outcomes in treating acute ischemic stroke due to large vessel occlusion (LVO) is directly linked to rapid reperfusion. Systems of care, improved imaging detection tools, and novel neuroendovascular devices are key innovations to faster treatment times. We assessed the impact of first pass reperfusion and procedure time on outcomes in the TIGER study.

Methods The TIGER study was a single arm, prospective, multi-center trial assessing the efficacy and safety of the Tigertriever, a radially-adjustable stent retriever, for LVO-related stroke. The trial enrolled 160 patients, of which 150 had successful mTICI 2 b-3 revascularization (94\%) at end of all procedures. Among patients with faster and slower times for last known well (LKW) to arterial puncture, arterial puncture to revascularization, and LKW to revascularization, we evaluated rates of modified first pass effect (mTICI 2b-3 after first Tigertriever pass), change in NIHSS by 24 hours, and functional independence (mRS 0-2) and freedom-from-disability (mRS 0-1) at 3 months. Symptomatic ICH, 90 days mortality and Embolization to new territory (ENT) were measured as well for safety evaluation.

Results Patient demographics, including age, gender, baseline mRS, baseline NIHSS and vessel occlusion location, were similar in all groups. Faster $(\leq 25 \mathrm{~min})$ compared with slower $(>25 \mathrm{~min})$ time from puncture-to-revascularization was strongly statistically associated with higher rates of first pass successful revascularization, nonsignificantly associated with greater $24 \mathrm{~h}$ delta NIHSS, and strongly statistically associated with functional independence and freedom from disability at 90 days. (Table 1) In contrast, faster ( $\leq 178 \mathrm{~min}$ ) compared with slower $(>178 \mathrm{~min})$ time from LKW-to-puncture and

\begin{tabular}{|c|c|c|c|c|c|c|c|c|}
\hline Group & & $\begin{array}{l}\text { mTICl } 2 b-3 \text { After } \\
\text { first Tiger pass }\end{array}$ & $\begin{array}{l}\Delta \text { NIHSS @ } \\
24 \text { hrs }\end{array}$ & $\begin{array}{l}\text { mRS } 0-2 @ \\
90 \text { days }\end{array}$ & $\begin{array}{l}\text { mRS 0-1@ } \\
90 \text { days }\end{array}$ & $\begin{array}{l}\text { sICH @ } 24 \\
\text { hours }\end{array}$ & $\begin{array}{l}\text { Mortality@ } \\
90 \text { days }\end{array}$ & ENT \\
\hline Arterial puncture to & $\leq 25 \mathrm{~min}, 52 \%$ (median 17 ) & $87.5 \%$ & -10.3 & $73.5 \%$ & $66.2 \%$ & 0 & $11.1 \%$ & $1.4 \%$ \\
\hline \multicolumn{9}{|l|}{ Revascularization } \\
\hline & $>25$ min, 48\% (median 44) & $34.8 \%$ & -8.3 & $51.5 \%$ & $33.3 \%$ & $2.9 \%$ & $19.7 \%$ & $4.5 \%$ \\
\hline & $P$ value & 0.00001 & 0.14 & 0.009 & 0.0001 & 0.13 & 0.16 & 0.28 \\
\hline \multirow{3}{*}{$\begin{array}{l}\text { LKW to Arterial } \\
\text { puncture }\end{array}$} & $\leq 178 \mathrm{~min}, 50 \%$ (median 125$)$ & $56.8 \%$ & -9.9 & $57.1 \%$ & $47.1 \%$ & $1.3 \%$ & $14.9 \%$ & $1.4 \%$ \\
\hline & $>178$ min, $50 \%$ (median 291.5) & $63.0 \%$ & -7.7 & $63.0 \%$ & $47.9 \%$ & $2.7 \%$ & $18.9 \%$ & $4.1 \%$ \\
\hline & $P$ value & 0.44 & 0.11 & 0.47 & 0.92 & 0.55 & 0.51 & 0.31 \\
\hline LKW to & $\leq 220 \mathrm{~min}, 50 \%$ (median 151.5$)$ & $64.3 \%$ & -10.5 & $62.1 \%$ & $50.0 \%$ & 0 & $14.5 \%$ & $1.4 \%$ \\
\hline \multicolumn{9}{|l|}{ Revascularization } \\
\hline & $>220$ min, 50\% (median 320) & $60.3 \%$ & -7.7 & $63.2 \%$ & $50.0 \%$ & $2.9 \%$ & $15.9 \%$ & $4.3 \%$ \\
\hline & $P$ value & 0.63 & 0.09 & 0.90 & 1.00 & 0.15 & 0.81 & 0.31 \\
\hline
\end{tabular}


faster $(\leq 220 \mathrm{~min})$ compared with slower $(>220 \mathrm{~min})$ time from LKW to revascularization were not associated with statistically significant differences in outcome. There were no statistically differences in safety outcomes in faster compared to slower times.

Conclusions Among patients with acute ischemic stroke due to large vessel occlusion, faster time from arterial puncture to revascularization is strongly associated with improved angiographic and 3 month clinical outcomes. These data emphasize the importance of rapid and efficient catheter navigation, device deployment, and clot retrieval for best patient outcomes.

Disclosures A. Jadhav: None. R. Gupta: None. E. Levy: None. O. Zaidat: None. D. Yavagal: None. J. Saver: None.

\section{P-022 ENDOVASCULAR TREATMENT OF WIDE-NECK BIFURCATION ANEURYSMS: A SINGLE-CENTER EXPERIENCE AND PARADIGM SHIFT}

A Copelan*, J Delgado Almandoz, Y Kayan, J Scholz. Neurointerventional Radiology, Abbott Northwestern Hospital, Minneapolis, MN

\subsection{6/neurintsurg-2021-SNIS.58}

Purpose To present our single center experience utilizing balloon-assisted coiling (BAC), stent-assisted coiling (SAC) and Woven Endo-Bridge (WEB) embolization for the treatment of both ruptured and unruptured wide-necked bifurcation aneurysms (WNBAs) with a focus on the safety and efficacy profiles of each technique.

Methods We retrospectively reviewed all WNBAs treated at our institution with BAC, SAC, and WEB embolization between January 2012 and August 2020. Required aneurysm characteristics were in line with the pivotal WEB Intrasaccular Therapy (WEB-IT) study and included: ruptured or unruptured status; size of dome between $3 \mathrm{~mm}$ and $10 \mathrm{~mm}$; wide-neck defined by neck size $\geq 4 \mathrm{~mm}$ or dome-to-neck ratio $<2$; and location limited to the basilar tip (BTA), internal carotid artery terminus (ICA-T), anterior communicating artery complex (ACOM), and middle cerebral artery (MCA) bifurcation. We collected patient demographic variables, aneurysm characteristics, intraprocedural technical difficulties (ITDs), perioperative complications, and aneurysm occlusion rates. Group differences were assessed and logistic regression models were utilized to analyze more complex relationships.

Results Three hundred one aneurysms met inclusion criteria and included 141 in the BAC group, 81 in the SAC group, and 79 in the WEB group. Nearly $27 \%$ of aneurysms were ruptured and the mean maximum aneurysm size was $6.3 \mathrm{~mm}$ $( \pm 1.9 \mathrm{~mm})$, mean neck $3.4 \mathrm{~mm}( \pm 1.3 \mathrm{~mm})$, and dome-to-neck ratio $1.6( \pm 0.5)$. There was a $6 \%$ incidence of ITDs in the WEB cohort, significantly less than the $17 \%$ incidence in SAC $(p=0.03)$, and resulting new persistent neurological deficits occurred in 5\% of SACs and 4\% of BACs, higher than the WEB cohort in which there were none, and this approached statistical significance $(p=0.09)$. Adequate aneurysm occlusion rates were achieved at significantly higher rates with SAC (90\%) and WEB embolization (85\%) compared to BAC (75\%) $(\mathrm{p}=0.014)$.

Conclusion The WEB device is a valuable addition to the neurointerventionalist's armamentarium, permitting adequate occlusion of challenging WNBAs often not suitable for BAC and with an improved safety profile relative to SAC.

Abstract P-022 Table 1 Procedure time, procedural related complications and clinical outcomes

\begin{tabular}{|c|c|c|c|c|c|}
\hline & $\begin{array}{l}\text { BAC } \\
(n=141)\end{array}$ & $\begin{array}{l}\text { SAC } \\
(n=81)\end{array}$ & $\begin{array}{l}\text { WEB } \\
(\mathrm{n}=79)\end{array}$ & TOTAL & P-values \\
\hline Procedure time (mins) & $\begin{array}{l}51.1 \pm \\
25.7\end{array}$ & $\begin{array}{l}86.6 \pm \\
38.5\end{array}$ & $\begin{array}{l}46.5 \pm \\
25.3\end{array}$ & $\begin{array}{l}61.6 \pm \\
35.4\end{array}$ & $\begin{array}{l}0.282 \\
<0.001\end{array}$ \\
\hline $\begin{array}{l}\text { Intraprocedural technical } \\
\text { difficulties: }\end{array}$ & $10(7.1 \%)$ & $\begin{array}{l}14 \\
(17.2 \%)\end{array}$ & $5(6.3 \%)$ & $\begin{array}{l}25 \\
(8.3 \%)\end{array}$ & $\begin{array}{l}0.823 \\
0.032\end{array}$ \\
\hline Thromboembolic event & $4(2.8 \%)$ & $8(9.9 \%)$ & $5(6.3 \%)$ & $\begin{array}{l}17 \\
(5.6 \%)\end{array}$ & $<0.001$ \\
\hline $\begin{array}{l}\text { Intraprocedural aneurysm rupture } \\
\text { or vessel perforation }\end{array}$ & $4(2.8 \%)$ & $2(2.5 \%)$ & $0(0 \%)$ & $\begin{array}{l}6 \\
(2.0 \%)\end{array}$ & \\
\hline Device migration & $2(1.4 \%)$ & $1(1.2 \%)$ & $0(0 \%)$ & $\begin{array}{l}3 \\
(0.9 \%)\end{array}$ & \\
\hline $\begin{array}{l}\text { Coil stretching/premature } \\
\text { detachment }\end{array}$ & $0(0 \%)$ & $3(3.7 \%)$ & $0(0 \%)$ & $\begin{array}{l}3 \\
(0.9 \%)\end{array}$ & \\
\hline $\begin{array}{l}\text { Clinically significant deficit } \\
\text { resulting from intraprocedural } \\
\text { technical difficulty }\end{array}$ & $6(4.3 \%)$ & $4(4.9 \%)$ & $0(0 \%)$ & $\begin{array}{l}10 \\
(3.3 \%)\end{array}$ & $\begin{array}{l}0.090 \\
0.120\end{array}$ \\
\hline $\begin{array}{l}\text { Post-procedure neurological } \\
\text { complication }\end{array}$ & $5(3.5 \%)$ & $8(9.9 \%)$ & $3(3.8 \%)$ & $\begin{array}{l}16 \\
(5.3 \%)\end{array}$ & $1,0.21$ \\
\hline Perioperative infarction & $4(2.8 \%)$ & $6(7.4 \%)$ & $3(3.8 \%)$ & $\begin{array}{l}13 \\
(4.3 \%)\end{array}$ & 0.723 \\
\hline Intracerebral hemorrhage & $1(0.7 \%)$ & $2(2.5 \%)$ & $0(0 \%)$ & $\begin{array}{l}3 \\
(0.9 \%)\end{array}$ & \\
\hline $\begin{array}{l}\text { Clinically significant deficit } \\
\text { resulting from post-procedure } \\
\text { complication }\end{array}$ & $2(1.4 \%)$ & $4(4.9 \%)$ & $1(1.3 \%)$ & $\begin{array}{l}7 \\
(2.3 \%)\end{array}$ & $1,0.367$ \\
\hline $\begin{array}{l}\text { Major disabling neurological } \\
\text { complications }\end{array}$ & $8(5.7 \%)$ & $5(6.2 \%)$ & $1(1.3 \%)$ & $\begin{array}{l}14 \\
(4.7 \%)\end{array}$ & $\begin{array}{l}0.162 \\
0.210\end{array}$ \\
\hline Procedure related death & $1(0.7 \%)$ & $2(2.5 \%)$ & $0(0 \%)$ & $\begin{array}{l}3 \\
(1.0 \%)\end{array}$ & $1,0.497$ \\
\hline
\end{tabular}

*When a single $p$-value is provided, this corresponds to a global value for BAC vs. SAC vs. WEB † When two $p$-values are provided, the first value corresponds to WEB vs. BAC and the second value corresponds to WEB vs. SAC

Abstract P-022 Table 2 Angiographic occlusion and retreatment

\begin{tabular}{llllll}
\hline & $\begin{array}{l}\text { BAC } \\
(\mathbf{n}=120)\end{array}$ & $\begin{array}{l}\text { SAC } \\
(\mathbf{n}=73)\end{array}$ & $\begin{array}{l}\text { WEB } \\
(\mathbf{n}=71)\end{array}$ & TOTAL & P-values \\
\hline Complete occlusion & $47(39.2 \%)$ & $64(87.7 \%)$ & $40(56.3 \%)$ & $\begin{array}{l}151 \\
(57.2 \%)\end{array}$ & $<0.001$ \\
& & & & $65(24.6 \%)$ & $<0.001$ \\
Neck remnant & $43(35.8 \%)$ & $2(2.7 \%)$ & $20(28.2 \%)$ & 0.014 \\
Adequate Occlusion & $90(75.0 \%)$ & $66(90.4 \%)$ & $60(84.5 \%)$ & 216 & 0.014 \\
Aneurysm remnant & $30(25.0 \%)$ & $7(9.6 \%)$ & $11(15.5 \%)$ & $48(18.2 \%)$ & 0.014 \\
Aneurysm & $21(17.5 \%)$ & $4(5.5 \%)$ & $6(8.5 \%)$ & $31(11.7 \%)$ & 0.014 \\
Retreatment & & & & & \\
\hline
\end{tabular}

†For complete occlusion and neck remnant, the p-values provided correspond to a global value for $B A C$ vs. SAC vs. WEBțFor adequate occlusion, aneurysm remnant, and aneurysm retreatment, the $p$-values correspond to WEB + SAC vs. BAC 